\title{
The Early Diagnosis of Gastrointestinal Cancers: From Canine Sniffing to Volatile Gas Analysis
}

\author{
Mohamed Alshekhani* \\ Department of Medicine, University of Sulaimaniyah, Iraq
}

Submission: April 10, 2018; Published: September 17, 2018

"Corresponding author: Mohamed Alshekhani, Kurdistan center for GEH, College of Medicine, Department of Medicine, University of Sulaimaniyah, Sulaimaniyah-Iraqi Kurdistan-Iraq, Email shaikhanimohammad@googlemail.com

\begin{abstract}
The innovative approach in using dogs to detect early cancer had paved the way for the laboratory detection of these volatile substances smelled by the dogs to overcome the inconvenient and non-practical use of dogs in clinical practices, although it can be a desirable approach in areas with limited resources or limited access, like the poor developing countries.
\end{abstract}

Keywords: Cancer; Volatile substances; Patients; Sweat; Medicine; Medical funds; Prostate cancer

Abbreviations: Cancer; Volatile substances; Patients; Sweat; Medicine; Medical funds; Prostate cancer

\section{Introduction}

The sensitive canine sense of smell (termed sometimes as electronic noses) had been used to use dogs to detect the odor of volatile compounds characteristic of patients with cancer by smelling breath, urine, stool of sweat, a principle like the use of these animals for criminal detection purposes. A variety of animal species were used in medicine to detect diseases, such as tuberculosis and cancer [1-5]. This method has the greatest appeal in communities where medical funds and accessibility are limiting, in diagnosis of serious disease for which no screening programs exist or the current biomarkers are not ideal. Dogs are trained to recognize the smell of skin, breath or urine samples from patient with different kinds of cancers including colorectal, pancreatic, breast, prostate, melanoma \& lung cancers. The dog's sniff is the most scent-detector "device" and have the potential to offer a noninvasive alternative to PSA sampling and prostate biopsy for detecting Prostate cancer. This method for the screening of tumor in human body is a painless, noninvasive and fast method \& does not need the biochemical analysis in clinical laboratories. It uses the odors that emanate from urine, breath, and feces. These compounds are metabolic products and/or consequence of bacterial dysbiosis produced by the disease state. The accuracy of canine scent detection was even higher for early-stage colorectal cancers and Canine scent detection was not confounded by current smoking, benign colorectal disease, inflammatory disease or the presence of human hemoglobin or transferring. Dogs can be trained to distinguish patients with bladder cancer on the basis of urine odour more successfully than would be expected by chance alone, suggesting that tumor related volatile compounds are present in urine, with characteristic odour signature distinct from those associated with secondary effects of the tumor, such as bleeding, inflammation, and infection. A positive correlation was found between dog sniff of or lung cancer detection and the ethyl acetate and 2-pentanone content of breath detected by chromatography. The methods presented for detection of lung cancer markers in exhaled air could be used as a potential noninvasive tool for screening and the canine method is relatively simple and inexpensive in comparison with chromatography [68].

Since the use of dogs to smell humans to detect their cancer early, seems to be not practical, unconventional and unsuitable for clinical application, but provide inspiration for more traditional laboratory investigations and there were trials to find the volatile substances smelled by dogs and analyze them in the laboratory. Analysis of substances present in exhaled breath is easier to perform, faster and non-invasive than serum biomarkers used for cancer detection. Several volatile organic compounds (VOCs) recognized as potential cancer biomarkers, by different analytical techniques are used such as gas chromatography coupled with mass spectrometry (GC/MS), ion flow tube mass spectrometry (SIFT-MS), proton transfer reaction mass spectrometry (PTRMS) and ion mobility spectrometry (IMS). Urine specimens were recently used to discriminate healthy individuals from patients with pancreatic ductal adenocarcinoma through the detection of Volatile Organic Compounds, with the ability to separate healthy from early stage and early stage versus advanced disease [8-11]. 


\section{References}

1. Yoel U, Gopas J, Ozer J, Peleg R, Shvartzman P (2015) Canine Scent Detection of Volatile Elements, Characteristic of Malignant Cells, in Cell Cultures. Isr Med Assoc J 17(9): 567-570.

2. Arasaradnam RP, Wicaksono A, O’Brien H, Kocher HM, Covington JA (2018) Noninvasive Diagnosis of Pancreatic Cancer Through Detection of Volatile Organic Compounds in Urine; Gastroenterology 154: 485487.

3. Agnieszka Ulanowska, Tomasz Ligor, Monika Michel, Bogusław Buszewski (2010) Hyphenated and Unconventional Methods for Searching Volatile Cancer Biomarkers. Ecological Chemistry and Engineering 17(1).

4. Anindita Bhadra (2011) Woof! Smells like cancer. Current Science 101(4).

5. Taverna G, Tidu L, Grizzi F (2015) Sniffing out prostate cancer: a new clinical opportunity. Cent European J Urol 68(3): 308-310.

6. Marije K Bomers, Michiel A van Agtmael, Hotsche Luik Canine, Merk C van Veen, Christina MJE, et al. (2012) Using a dog's superior olfactory sensitivity to identify Clostridium difficile in stools and patients: proof of principle study. BMJ 345: e7396.

7. Teodoro-Morrison T, Diamandis EP, Rifai N, Weetjens BJ, Pennazza G, et al. (2014) Animal Olfactory Detection of Disease: Promises and Pitfalls. Clin Chem 60(12): 1473-1479.

8. Hideto Sonoda, Shunji Kohnoe, Tetsuro Yamazato, Yuji Satoh, Gouki Morizono, et al. (2011) Colorectal cancer screening with odour material by canine scent detection. Gut 60(6): 814-819.

9. Carolyn M Willis, Susannah M Church, Claire M Guest, W Andrew Cook, Noel McCarthy, et al. (2004) Olfactory detection of human bladder cancer by dogs: proof of principle study. BMJ 329: 712.

10. Ehmann R, Boedeker E, U Friedrich, J Sagert, J Dippon, et al. (2012) Canine scent detection in the diagnosis of lung cancer: revisiting a puzzling phenomenon. Eur Respir J 39(3): 669-667.

11. Bogusław Buszewski, Tomasz Ligor, Tadeusz Jezierski, Anna WendaPiesik, Marta Walczak, et al. (2012) Identification of volatile lung cancer markers by gas chromatography-mass spectrometry: comparison with discrimination by canines. Anal Bioanal Chem 404(1): 141-146.

\section{Your next submission with JuniperPublishers will reach you the below assets}

- Quality Editorial service

- Swift Peer Review

- Reprints availability

- E-prints Service

- Manuscript Podcast for convenient understanding

- Global attainment for your research

- Manuscript accessibility in different formats

( Pdf, E-pub, Full Text, audio)

- Unceasing customer service

Track the below URL for one-step submission

https://juniperpublishers.com/online-submission.php 